\title{
POLÍTICAS NEOLIBERALES Y DERECHOS FUNDAMENTALES. UN APUNTE REFLEXIVO: VIDA COMUNITÁRIA, SINDICALISMO Y GLOBALIZACIÓN. UN POCO DE ISRAEL, JAPÓN Y BRASIL
}

\author{
Roland Hasson*
}

RESUMO: Este texto, resultado de palestra, traz o relato de uma experiência de vida comunitária com vistas a propor uma reflexão sobre sindicalismo e globalização.

Lo que se percibe, en un último análisis, es que donde no haya respeto por la vida y por la integridad física y moral del ser humano, donde las condiciones mínimas para una existencia digna no sean garantizadas, donde no haya limitación del poder, en fin, donde la liberdad y la autonomía, la igualdad (en derechos y dignidad) y los derechos fundamentales no sean reconocidos y minimamente asegurados, no habrá espacio para la dignidad de la persona humana y esta (la persona), a su vez, podrá no pasar de mero objeto de albedrío e injusticias. SARLET, Ingo Wolfgang. Dignidade da pessoa humana e direitos fundamentais na Constituição Federal, p. 59.

Cuando se habla en derechos fundamentales, hay que tener en mente la vida en sociedad. Más que eso, hay que tener en mente la solidaridad de las personas, la solidaridad de la sociedad como un todo, a favor de cada uno.

Cuanto más solidarioel ciudadano, el pueblo y la nación, más valorizados y respectados serán los derechos fundamentales.

Con base en este entendimiento quiero contarles una historia que yo viví quando

\footnotetext{
* Advogado e Procurador do Estado do Paraná. Mestre e Doutor em Direito pela UFPR. Professor do Programa de Pós-Graduação em Direito da PUCPR.
}

era un chico de 19 años de edad. Estaba estudiando el segundo año de la facultad de Derecho en la Universidad Federal del Paraná. Y también en mi segundo año de prácticas en el despacho de abogacía Professor Doutor João Régis Fasbender Teixeira. Decidí que quería conocer el mundo. Interrumpí la matrícula en la facultad, dije adiós a mis amigos del despacho, vendí el coche que mis padres me habían dado y embarqué en un avión para Israel.

Escogí Israel porque yo soy judío, y también porque Israel era un país nuevo, por eso ellos recibían todo tipo de persona, judía o no, para trabajar en el Kibbutz. Pronto contaré lo que es un Kibbutz. 
Viajando por KLM, hicimos una parada en Libéria ((Norte de África), en Holanda y en Grecia, donde cambiamos de avión, y seguimos volando por la EL-AL, compañía israelense. En Atenas, tuvimos una gran entrevista y revisaron nuestro equipaje. Muy curioso el hecho de retrasarse avión adrede y permanecer en un local más distante, diferente del local común, para prevenir atentados. A esta hora, claro, yo ya estaba emocionado, aprovechando cada cosa que ocurría, sin pensar en cualquier tipo de peligro.

Cuando llegamos a Israel, fuímos directamente al Kibbutz. Yo intentaré explicar lo que es. Entonces:

Imaginen un pueblo que recibió de Dios una tierra prometida. Ese pueblo se dispersó por el mundo, una parte allí se quedó, pero siempre tuvo en sus pensamientos volver a la tierra prometida. Crearon el Movimiento Sionista, en el siglo XVIII, que defendía esta idea.

Muchas familias de distintas partes del mundo, principalmente de Europa, empezaron a moverse hacia Israel.

Con poco dinero, aproximadamente diez jovenes parejas partieron juntos. En Israel, compraron una porción de tierra para plantar. Contruyeron una casa para vivir y allí vivían, comían y plantaban, todos juntos.

Con el dinero de la próxima cosecha, decidieron que deberían construir un refectorio para que durmiesen y comiesen en el mismo sitio.

Parejas jovenes, muchas mujeres se quedaron embarazadas al mismo tiempo. Trabajaron hasta el nacimiento de sus hijos.

Después, decidieron que deberían hacer una casa para los niños y que las madres deberían alternarse para cuidar de ellos, porque su trabajo era muy necesario. Así hicieron, una casa para los niños, y las madres se alternaban para cuidar de ellos. Todo el dinero que ellos ganaban lo investían nuevamente en aquel lugar.

Después de algun tiempo y muchas cosechas, decidieron hacer, con el dinero que tenían, una casa para cada pareja.

Entonces se quedó en aquel lugar el refectorio en el centro, la casa de los niños y pequeñas casas, una para cada pareja.

El dinero era siempre nuevamente invertido, supliendo el Kibbutaz las necesidades de las personas.

Cuando tenían edad para estudiar, los niños merecieron la construcción de una escuela dentro del Kibbutz, primero las madres enseñaban, después los profesores.

Con las cosechas, las cosas no paraban de mejorar y construyeron una tintorería y un club con juegos y librería. Después una piscina, una cuadra de deportes, un cine, una discoteca.

Así es la vida en el Kibbutz hasta hoy. Una hacienda comunitária en la que el dinero sirve para suplir las necesidades de las personas. Hoy, en algunos Kibbutz, se puede abrir el grifo del refectorio y tener agua con gas.

Existe una pequeña tienda con dulces, cigarrillos y cada uno puede coger lo que necesita. No hay dinero en el Kibbutz.

Curioso es que junto conmigo, fueron más o menos quince brasileños.

Nos mostraron nuestro alojamento, dormitorios con baño, para tres personas cada uno. Cerca del alojamento, una encargada apontó un deposito donde había pequeñas cosas que podríamos querer para tener en nuestros dormitorios - chocolate, té, cigarrillos, caramelos, galletas,... Nos dijo 
que el refectório servía cinco refecciones cada día y que en el club también podríamos encontrar jugos, tés, bizcocho... y que aquello eran solamente algunas cositas para comer en el dormitorio y que siempre estarían allí, en el depósito.

Entonces: el prime brasileño que entró en la casa de aperitivos, se llevó la mitad. El segundo, se llevó la otra mitad y para el tercero nada sobró.

Llamaron a la encargada y ella pidió que dejasen las cosas allí nuevamente, pues en el dormitorio se estropearían y el depósito siempre estaría lleno. Pidió también para los que no fumaban que no cogiesen los cigarrillos pues así los que fumaban tendrían más.

No preciso decir el resultado. Nadie devolvió nada y la encargada tuvo que hacer fardos todas las semanas, uno para cada uno, y los entregaba una vez por semana. Aquellos que no fumaban cogían cigarrillos y los vendían a los que fumaban.

Todos en el Kibbutz trabajaban en todos los lugares. En el campo, plantando, cosechando frutas, con las vacas, dándoles comida, sacando la leche; en la cocina, cocinando y lavando platos, en la tintorería, en la tienda,...

Nadie cuida de nadie, cada uno hace su trabajo. Dijo, los brasileños, al principio, no entendieron muy bien el sistema. Muchos de ellos no hacían mucha cosa porque no había nadie para controlarlos, dormían en la hora de cosechar,... Pero esto no duró mucho porque si no trabajaban no tenían nada que hacer. Todos estavan trabajando y los brasileños aprendieron a trabajar también, sin ninguna imposición.

Ahora que yá expliqué lo que es un Kibbutz, aclarando que hay más de mil en Israel, algunos con industrias dentro, les digo que el Estado de Israel nació después del Sindicato.

Como el Kibbutz, los otros sectores de la sociedad, se estructuraron así. Tuvo un grupo que decidió comprar un autobus y después otro y otro, construyendo una cooperativa en que los proprios dueños los conducían.

Todos empezaron a ayudar para contruier un hospital. Crearon un gran sindicato que recogía contribuciones y cuidaba de las necesidades de los sindicalizados. Todos necesitaban sindicalizarse pues el sindicato era de ellos. El sindicato, llamado Histadrut, además de anteceder al estado de Israel es hoy el dueño de la gran rede de hospitales de Israel, dueño de las escuelas, de las industrias, del transporte, de los bancos,...

Lo que podemos ver es las garas de las personas que tienen un objetivo, movidas por una necesidad, actuando seriamente y con fraternidad. Podemos decir que muchos gobiernos intentaron estatificar por lo menos la rede de hospitales. No lo consiguieron hasta hoy. Podemos decir también que la Histadrut es una fuerza paralela al gobierno de Israel, tiene como objetivo el bienestar de los trabajadores y lucha con todas sus fuerzas para que esto sea realidad. Israel, es entonces un gran sindicato.

Puedo definir Israel en algunas líneas que escribí cuando aún estaba allí y que puede mostrar el sufrimiento de aquel pueblo, donde hombres y mujeres son guerreros, sirviendo al ejército, las mujeres durante dos años y los hombre durante tres años en un estado constante de guerrilla:

Una bella mañana. El sol fuerte en la cabeza de las personas que caminaban por las calles de aquell infierno. 
Sensación de libertad en la cara de las personas, que com sus ojos angustiados sonreían a sus hijos, más libres que ellos, poque no sabían su destino.

Y la vida continuaba, continúa y quizás continuarái Quién puede saberlo?

Las plazas continuaban llenas y la sensación de libertad, las más rica marca de este pueblo, se extendía con el viento hasta las fronteras de aquell infierno.

Todos viven una vida muy intensa. Ellos trabajan com amor, comen con amor y también pelean con amor.

No hay frío en el infierno, ni lluvia, ni otras cosas del tiempo que estamos acostumbrados a reclamar.

Allí todo es aceptado, tiene que ser aceptado y aún más tiene que ser aceptado con amor.

Para muchos, debe de ser terrible vivir en el infierno; principalmente cuando esto es una opción; porque todos tienen el derecho de escoger su camino.

Entretanto, se puede decir todo en una sola frase: "ser o no, es la cuestión".

Llegando a Japón, veremos que su historia no es muy diferente de la historia de Israel. Japón es una isla, la verdad es que son por lo menos cuatro grandes islas conectadas. Tiene una cultura milenar y enfrentó seiscientos años de guerrilla civil, por causa de la búsqueda del poder. A pesar del Emperador, el poder estaba en las manos de los "shogun", grandes capitalistas que tenían muchas tierras donde cultivaban arroz. Ellos tenían sus ejércitos comandados por samurais. El Emperador, incluso teniendo el respeto de todos, jamás tuvo el poder de gobernar Japón.

Muchas historias tengo para contar, pero voy a contar solamente sobre los días actuales, advirtiendo que el país fue enteramente devastado por la segunda guerra mundial.

Estuve en Japón en Julio de 99, por un intercambio regularizado entre la Pontifica
Universidad Católica del Paraná, Universidad Federal del Paraná, una Universidad Americana y una Universidad Japonesa.

La impresión que tuve fue la mejor posible.

Un país limpio, bonito, donde se respeta la naturaleza y el ser humano.

Como resultado de su cultura, el pueblo japonés aprecia la seriedad, la honestidad y la lealtad. La vergüenza es motivo de suicidio, y quién sabe sea por eso que ellos tienen tanto respeto y cuidado con todos.

Todos se esfuerzan en lo que hacen; ellos quieren siempre hacerlo bien hecho, cualquier cosa que hagan...

Me llamó la atención el hecho de que el pueblo japonés es politeista.

Pero, con tantos dioses, del mar, del sol, de las colinas,... se prioriza mucho el respeto a la naturaleza y al ser humano.

Hay un esfuerzo igual del pueblo y de cada uno sólo por la construcción de un país ideal. El derecho del trabajo como aquí lo llamamos no existe. Cuando se entra en una empresa, el japonés empieza a ser parte de una familia, y tiene orgullo de ostentar el símbolo de su empresa, como en el tiempo de los shoguns, cuando cada uno cargaba el brasan de su señor. Trabajaban las horas que les era necesario trabajar, sin pensar en una paga extra. El salario es ajustado todos lo años, pagado en parcelas menores todos los meses, teniendo dos gratificaciones que complementan el valor del año ajustado, pagadas en julio y diciembre. Las vacaciones empiezan con una semana por año, y después de algunos años de trabajo llegan a cuatro semanas. Están incluidas en el pago anual. 
Las grandes empresas tienen sindicatos que actúan como un conseio, resolviendo los problemas que surgen, incluso dentro de las empresas. En las escuelas y también en la universidad, los alumnos tienen tres horas de atividades físicas todos los días, desarrollando las artes marciais y el arco y flecha.

Es lógico que el analfabestismo no exista. Hay un respeto muy gran por los más viejos, que simpre auxilian en la construcción del país, por lo menos con trabajo voluntario. Los más viejos siempre son oídos en los foros de discusión. Puedo describir Japón con las siguientes palabras: en este mundo hay tantas cosas para hacer y tan pocas personas capaces de hacerlo, que debemos hacer lo mejor para que nuestra contribución tenga utilidad.

Adentrándonas al tema de la globalización y empezando a hablar de Brasil, tengo lo siguiente:

Vivimos en un mundo capitalista, globalizado.

Capitalista en el sentido de que la iniciativa privada puede todo, hace lo que quiere, en cualquier actividad vital o no a la sociedad. Globalizado, en el sentido de no existir ninguna barrera a la circulación del capital, incluidas las taxas y más, direccionando para el fin de todas las restricciones de barreras comerciales.

El Estado intervencionista y social está disminuyendo, incluso en los paises más ricos. Se cayó el muro de Berlin, y con ello la competición entre los sistemas opuestos.

Me acuerdo de un libro escrito en la década de 1970, en el clímax de la guerra fría, llamado "La Revolución Mediata", donde el autor dijo que la "revolución social" no ocurriría solamente en la "União Soviética" que aún existía en aquella época, pero que ocurriria, o mejor, estaba ocurriendo en los Estados Unidos de América.

Dijo el autor que lo más socialista de los paises eran los Estados Unidos de América, que rápidamente acabaron con todo un sistema social repartido entre pobres y ricos, negros y blancos, judíos y católicos, americanos y extranjeros,... partiendo rápidamente para la socialización de su país.

Esto ocurrió realmente.

El acceso a la escuela se volvió mayor y sin restricciones, sin ninguna discriminación entre ricos y pobres, negros y blancos, extranjeros y americanos. La escuela pública se volvió realmente pública, con acceso general en cualquier nivel de enseñanza.

La salud, igualmente, recibió el mismo tratamiento, socializado.

Se garantizó también el acceso a la habitación, con financiamiento subsidiado, con plazos de treinta años.

Las carreteras públicas, recibieron muchas inveisiones, lo que permitió el libre tránsito por todo el país.

Realmente, los Estados Unidos se convirtieron en el más socialista de los paises capitalistas.

A su vez, los demás paises capitalistas del mundo, Alemania, Japón, Francia,... siempre garantizaron el acceso público a la educación, salud, habitación, teniendo en sus paises una buena estructura general y de correteras.

Seria lógico preguntarnos cual es el Estado que no tiene un sistema público de educación?

Igualmente, dónde y cómo puede la educación pública ser peor que la enseñanza privada? 
¿Dónde y cómo puede un hospital público ser peor que un hospital privado?

Esto porque, todos saben que el Estado es el mayor recaudador de dinero de la sociedad. Recauda más que cualquier empresa privada y quién sabe, más que todas ellas juntas. Sin embargo, no podemos olvidarnos de la idea de que, a pesar de mayores y más ricas, estas corporaciones no tienen el poder que el Estado tiene.

Ahí empeza un juego de ajedrez.

¿Qué buscan estas corporaciones? Solamente el lucro.

Se instalan donde pueden ganar más.

Pero, el poder, el poder está en las manos del Estado.

$\mathrm{Si}$ las corporaciones crean empleos y generan el desarrollo, por otro lado, ellas precisan instalarse, funcionar en algún lugar.

Esta claro que, si todos los Estados ofreciesen las mismas condiciones, sin ningún tipo de guerrilla fiscal, todos serían candidatos a abrigar tales corporaciones. Más que eso, la libre competencia haría con que aquellas corporaciones que no cuidasen de una cierta región tuviesen serios problemas de competencia, consecuencia del desarrollo de otra corporación.

Esas corporaciones no se limitan a algún ramo de actividaad, pero a todos los ramos desde la agricultura, ganadería, industrias pesadas, industrias leves, de alimentos, de bebidas, de dulces, de tabernas,...

Perciban que entiendo ser esta la única visión que se puede atribuir a este sistema.

De la misma forma, en la visión del estado, entiendo imposible atribuir al estado otras funciones que no sean el acceso general a la educación, salud, habitación y estructura general del país. El resto, el resto es superfluo, consecuencia de la realización completa de las funciones básicas y que, cuando completas, generan entonces la ingerencia, con la intención de desarrollar o incluso de invertir el capital en otras áreas.

Es posible pensar en una empresa aérea estatal, hoteles estatales,...

Sin embargo, para que esto ocurra, la base (educación, salud, habitación, estructura) debe estar lista. No se puede pensar en hacer todo al mismo tiempo. La falta de una línea aérea nacional permitiría la llegada de compañías aéreas internacionales, que seguirían las reglas nacionales (el poder del Estado) de operación. Los hoteles aumentarían también el desarrollo de posadas, la libre iniciativa y la competencia. No podemos olvidar que estamos hablando de lo que no es essencial para el Estado.

Incluso si hablamos de siderurgia, explotación del petroleo, telecomunicaciones esto no es efectivamente lo esencial del Estado. Es necesario sí, pero con su poder el Estado regula estas cuestiones de manera que las corporaciones le sirvan. Lo mismo se puede decir de la energía eléctrica.

Vean las leyes anti “Trust", usadas en todo el mundo y también en Brasil. Preguntamos entonces, ¿existe poder mayor que el estatal?

Está claro que nada impide que el Estado tenga una participación en estos sectores. Pero, el principal, repitiendo, es la educación, la salud, la habitación, y la estructura.

Los otros sectores de desarrollo ocurren con socios, corporaciones con capital, juntamente con el Estado, que va a asumir su papel con su poder regular o por contratos administrativos rizando la prevalencia, siempre, de la supremacia del estado. 
Es verdad que es necesario que el Estado tenga metas y directrices báscicas para todos los sectores necesarios al país y a la sociedad. Pero también, necesita cuidar de su papel principal, educación, salud, habitación, estructura.

\section{¿Y qué vemos en Brasil?}

Es esto que tenemos que pensar. Es cierto que tenemos que luchar por un amanecer más igual, no podemos mentir unos para los otros, apenas concienciarnas de que precisamos luchar y buscar lo mejor para todos. No podemos olvidar nos de las palavra del padre Lebret:

"El mundo es así: dos tercios de la humanidad no durme porque tiene hambre, y otro tercio no durme com miedo de los que tienen hambre. Para donde se dirigen las esperanzas y la revuelta, de estos dos tercios, para allá irá la humanidad."

¿Y qué estamos haciendo para mudar cambiar situación?

Nada. Tenemos un Congresso Nacional que lleva años para soluciará cualquier cosa. Todo allí está parado.

Perciban que la propia Central Única de los Trabajadores - CUT - pretende la desreglamentación de los sindicatos, propiciando su libre creación, sin cualquier interferencia del Estado. ¿Hace cuantos años que esto está siendo pedido? Por lo menos desde 1985.

¿Cuál és el modelo sindical que tenemos hoy? El mismo, copiado por la Itália fascista y que allá cayó después de la Segunda Guerra.

En Brasil, solamente puede haber un sindicato de una misma categoría en una misma base que no puede ser menor que el área de un município. Tenemos aún el antiguo impuesto sindical, hoy llamado de contribuión sindical, que da el sustento a un gran número de sindicatos que solamente tienen directoría.

Dónde está la espontaneidad, la union real entre las personas buscando un objetivo. Todo ahí és limitado por la ley.

Me acuerdo de la creación del FGTS, que acabó con la estabilidad en el empleo.

La historia es muy simple y pocos la cuentan.

Brasil vivió su industrialización con el gobierno de Juscelino Kubitschek de Oliveira, que prometió dar un paso de cincuenta años en cinco años de gobierno.

Y realmente lo hizo.

Grandes industrias se instalaron en el país, o, si ya estaban instaladas, pasaron a produzir, todo empezó en 1956.

Nuestra Consolidación de las Leyes del Trabajo - CLT - garantizada la estabilidad en el empleo a los empleados que tuviesen diez años de trabajo en la misma empresa. Nuestros Tribunales, en esta epoca, ya creaban jurisprudencia, en el sentido de que las empresas no podrían despedir sin justa causa al empleado con nueve años de empleo.

Entonces:

Con la revolución - cuando los militares tomaron el poder derrubando al presidente Civil, acabando con los partidos políticos y terminando com el mandato de Senadores y Diputados, y aún después cerrando el Cogresso Nacional - se empezó a pensar en lo que se podría hacer para acabar con la estabilidad de los trabajadores en el empleo, lo que fue hecho, ciertamente, por presión de las industrias.

El embajador de Brasil fue llamado en Washington, Embaxador Roberto Campos, 
pasó a ocupar el cargo de Ministro de Planeamiento. Es de su autoria la ley que creó el Fonfo de garantía por El tiempo de Servicio - FGTS.

¿Y qué es o era la estabilidad?

Es cierto que el mayor bien que tiene el empleado es su empleo. Es lo que le da tranquilidad, es lo que le permite vivir, es lo que le permite hacer una compra con confianza, sabiendo que podrá pagarla porque tendrá su empleo, sino por el cometimiento de una falta grave.

El primero año del contrato de trabajo era de experiencia y si el trabajador era despedido no habían ninguna indemnización.

Después del primer año de trabajo, si el trabajador era despedido sin justa razón, tendría derecho a una indemnización, igual al valor del último y mayor salario recibido en la empresa, incluso en la indemnización el duodécimo del $13^{\circ}$ salário, por año o tiempo igual o superior a seis meses. Después de completar diez años de trabajo en la misma empresa - y en la jurisprudencia este tiempo estaba diminuyendo para 8, 9 años entendiendo proposital el despido sin justa causa - el empleado alcanzaba su estabilidad en el empleo, no prodría ser despedido sin justa causa.

El fin de su contrato solamente ocurriría com una razón justa, y ésta debería ser comprobada judicialmente, con expediente judicial para la averiguación de falta grave.

El empleado podría dormir tranquilo, podría hacer una compra con confianza, podría hacer planes y previsiones.

Esto sí, la estabilidad en el empleo, es el mayor bien que tiene el empleado.

Con la argumentación de que la indemnización solamente era pagada al empleado en los casos de dimisión sin justa razón antes de los diez años, empezarón a difundir la idea de que el FGTS era bueno a los que lo escogían.

El FGTS, decíon, que es de $8 \%$ sobre la remuneración del trabajador, o sea, con las usuras, un salário por año de trabajo siempre será del trabajador, incluso si fallece, si dimitiese, si se jubilase. Aún, en caso de despido sin justa razón el valor será más alto, con una multa, en la época, del $10 \%$. Finalmente, podrá utilizalo para el pagamento de devda de compra de casa propia.

Hubo un largo prazo para hacer la opción por el FGTS, ley creada en 1966 que empezó a regir en 01.01.67, siendo que la opición podría ser anterior a la fecha regimiento de la ley. La gran mayoria estable de los empleados escogió quizás por la gran divulgación de sus falsas ventajas, quizá por la presión del empleador.

Desde entonces, 1967, todo empleado que aentrava en cualquier empresa hacía la opición por el FGTS. A la verdade tendría que hacer esta opición, porque si la recusase no tendría el empleo.

Este mecanismo de "opción" por el FGTS permaneció hasta la Constitución de 1988, cuando acabaron con la hipocresía de la "opción", determinando que todos los empleados empezaban a formar parte del sistema de FGTS.

Se acabó de una sola vez con la estabilidad en el empleo.

Cuento esta historia para que podamos entender que el país está retrocediendo - o como algunos dicen, "flexibilizando" - hasta mucho tiempo, la legislación trabajista. 
En el Congreso nacional, desde hace muchos años, hay proyectos que garantizan la estabilidad, o que acaban con las posibilidades de dimisión sin justa razón, por la simple vonluntad del empleador.

Proyectos que determinan la posibilidad de finalización del contrato de trabajo siempre que exista un motivo, sea técnico, disciplinar, económico o financiero.

Pero nada de esto se pretende.

Es el opuesto, los vientos de la globalización llevan a los países del tercer mundo a la flexibilización, a la vuelta del "laisses faire, laisses passes".

Y ahí, quiero recordar los orígenes del derecho del trabajo, muy resumidamente:

1. El hombre siempre trabajó, para obtener sus alimentos o para protegerse de animales. Haciendo armas, empezó a utilizarlas para cazar y en luchas con otros hombres. En las luchas, verificó que en lugar de matar a los vencidos, era mejor hacerlos prisioneros, esclavos que, en un gran numero, eran alquilados o vendidos. Los servicios manuales eran considerados indignos.

En esto paso, el hombre era escravo de otro hombre.

2. El poder de los reyes y emperadores, con las fuerzas de sus ejércitos, los llevaron a conquistar grandes áreas de tierras. Divididas en glebas, las daban a los señores feudales que cobraban de aquellos que moraban en sus tierras impuestos caros, y más que eso, tendrían derechos sobre ellos; incluso siendo libres, no tenían permiso para salir de las tierras.

Ahí el hombre era escravo de la tierra.
3. La necesidad de huir del campo, donde el poder de los nobles era prácticamente absoluto, hizo que la población se amontonase en las ciudades libres. El hombre, que hasta entonces trabajaba para el señor de la tierra, teniendo para sí la alimentación, el vestuario y la habitación, empezó a tener su actividad organizada, pero aún sin completa liberdad. Aprendices, compañeros y maestros, solamente podrían ejercer la profesión aquellos escritos en las Corporaciones de Ofício. Los reyes dieron fuerza a las corporaciones para debilitar a los nobles. Más tarde, disminuyeron los derechos de las corporaciones, quizás para evitar su influencia, quizás para reducir la suerte de los aprendices y trabajadores. El sistema no era más que una fórmula más blanda de esclavizar al trabajador, habiendo dimensiones dentro de la corporación o entre las corporaciones, que luchaban para mantener los privilegios.

La lucha o la liberación del tabajador tendría que ser hecha más tarde, como consecuencia de la revolución industrial y de la generalización del trabajo asalariado, una nueva lucha, no más contra el maestro de la corporación, pero sí contra el patrón, el capitalista, apoyado por el Estado, en su función de fiscal de la ley y aplicador de la justicia.

4. La invención de la máquina y su aplicación a la industria revolucionaron los métodos de trabajo y consecuentemente, las relaciones entre patrón y trabajadores. Mano de obra abundante, hacía con que los salarios se quedasen bajos. En esta época, el mundo vivia los ideales de la Revolución Francesa. El Estado se volvió liberal. 
Pero la libertad y la igualdad como conceptos abstractos ocasionaban la aceptación del concepto de Fouillé "quien dice contractual dice justo" y se insistió en una nueva forma de esclavitud, con el crecimiento de las fuerzas de los privilegiados de la fortuna y la sevidon y opresión de los más débiles. Se formaban dos clases distintas: la proletária y la capitalista. La primera, más numerosa, no tenía poder, en el régimen que el Estado solamente garantizaba en el plano teórico, la igualdad y la libertad. La clase capitalista, por la fuerza del dinero, por la submisión por el hambre, imponía al proletariado la orientación que había de ser seguida.

La minoria capitalista - patronal - no se preocupaba con la condición de vida de sus empleados.

Mientras, los pensadores sempazaron a manifestarse contra la situación, traducida en las palabras de Ripert "la experiencia muestra que la libertad no es suficiente para garantizar la igualdad, pues los más fuertes rápidamente se convierter en opresores. Y Palacios definió bien lo que ocurrió: "la libertad sin frenos será la razón de la brutalidad y de la usurpación si hay desigualdad en las fuerzas individuales" y reafirmaba el precepto de Lacordaire: "entre el fuerte y el débil, el rico y el pobre, es la libertad que esclaviza y la ley que libera".

5. La caida del Estado liberal tuvo inicio con los estudios del colectivismo y otros de construcción social con base en el Estado Autoritário y algunos hablando del equilibrio de las classes. Roberto Owen, Kingsley, Thomas Crlyle, Saint Simon, Pacqueur, Vidal, Colin, Cesar de Poppe, Adolfo Wagner y Karl Marx.
La Iglesia, por medio del Papa Leão XIII, publica la Encíclica “Rerum Novarum”, que impresionó al mundo cristiano, incentivando el interés de los gobernantes por las clases trabajadoras.

Como órgano máximo del derecho, el estado debería, en la nueva concepción, volvesse el instrumiento de la Justicia de la Sociedad, interviniendo como representante de los derechos colectivos, para contener y reprimir los interesses individuales privados y mantener el equilibrio entre los diversos factores de la produción y por lo tanto ver un mejor reparto de las riquezas, base del bienestar social.

Gana fuerza la doctrina intervencionista. En nombre de la solidaridad, la igualdad es sustituida por la pura igualdad jurídica, como regla de derecho.

6. Los trabajadores tomaban posición para pedir los beneficios que les eran debidos. Permanecía el espírito sindical; huelas y luchas entre el pueblo y la policía, estas movimientadas por la clase capitalista. La voz de los trabajadores ya era oída en el parlamento. O el Estado asumía y abandonaba su inactividad o acababa detruído por la población. Las agitaciones, las rezas de la Iglesia, la palabra de los estudiosos hacía con que se comprendiesen las pretensiones de los trabajadores.

Con la primera gran guerra, todos comprendieron que los trabajadores habían caído en los campos de guerra, luchando no solamente para defender las riquezas de los detentores del capital, sino también preparando el campo para una nueva sociedad en que ellos tendrían los mismos derechos 
que tendrían todos los ciudadanos, en que el trabajo estuviese en el mismo plano del capital. El Tratado de Versailles, de 28.06.1919 instituyó el Trabajo, la OIT.

Y ahí llegamos a las Convenciones Internacionales del Trabajo, que Brasil, en su gran mayoría, se olvida. Es suficiente recordar la Convención de 158, que después de aprobada - lo que ocurrió ciertamente por un descuido, fue inmediatamente denunciada. Esta Convención garantizaba la estabilidad, excluyendo por motivos disciplinares, técnicos, económicos, o financeros, y adoptando normas para la dispensa colectiva.

Nosotros sabemos lo que queremos para Brasil, nuestro país. Pero no conseguimos descubrir quien es son los detentores de las fuerzas que impidem al país tener una solidaridad entre las personas y entre estas y las empresas.

Bien, lo que importa es que no estamos aislados. Lo que vimos sobre la estabilidad es suficiente para que podamos tener una noción de lo que pasa aquí en Brasil, donde, como en todo el mundo, el capital sofoca los que no tienen nada más que su fuerza de trabajo.

Creo que solamente podemos tener en cuenta la solidaridad de los demás trabajadores del mundo.
Debemos caminar para un sindicalismo fuerte y espontáneo.

Debemos adoptar la globalización y unirmos a los sindicatos extranjeros. Mostrarles a, nuestros colegas empleados, en sus paises, lo que ocurre en nuestro país.

Debemos sí, globalizar los sindicatos.

Si actuamos así, estaremos resguardando la dignidad, bien mayor y fundamental del hombre.

Termino con un pequeño escrito que hice en algunas de mis reflexiones:

El ser humano valoriza lo que tiene.

El ser humano no percibe quién está alrededor.

Todo ocurre sin que lo percibamos.

Rutina, rutina y nada más...y todo bien.

De repente, pero de repente, el castillo cayó, Si ningún motivo.

Viene la tristeza, la muerte interior.

Pero com ellas, la percepción de lo que había alrededor.

Resurge el sentimiento de lucha, de valorizar lo que está alrededor,

Resurge la fuerza para buscar nuevamente, sin egoismo.

Recontruier, ayudar, percibir nuevamente el amor que existe.

Trabajador, gente, persona, ser humano. No un número, sino un igual, la verdadera alegría,

Un cambio de felicidad. 
